\title{
A novel recessive hyperekplexia allele GLRA1 (S231R): genotyping by MALDI-TOF mass spectrometry and functional characterisation as a determinant of cellular glycine receptor trafficking
}

\author{
Andreas Humeny ${ }^{1,4}$, Thomas Bonk ${ }^{1,4}$, Kristina Becker ${ }^{1}$, Mehrdad Jafari-Boroujerdi ${ }^{2}$, \\ Ulrich Stephani $^{2}$, Klaus Reuter ${ }^{1,3}$ and Cord-Michael Becker*,1 \\ ${ }^{1}$ Institut für Biochemie, Emil-Fischer-Zentrum, Friedrich-Alexander-Universität Erlangen-Nürnberg, D91054 \\ Erlangen, Germany; ${ }^{2}$ Klinik für Neuropädiatrie, Christian-Albrechts-Universität Kiel, D-24105 Kiel, Germany
}

Hyperekplexia or startle disease (stiff baby syndrome, STHE) is a hereditary neurological disorder characterised by an exaggerated startle response and infantile muscle hypertonia. Several autosomal dominant and recessive forms of the disorder have been associated with point mutations in GLRA1, the human gene encoding the $\alpha 1$ subunit of the inhibitory glycine receptor. Here, we describe a recessive point mutation (C1073G) in exon 7 of GLRA1 leading to an amino acid exchange of serine 231 to arginine in transmembrane region TM1. The mutation was detectable by restriction digest analysis of genomic PCR amplimers by matrixassisted laser desorption/ionisation time-of-flight mass spectrometry (MALDI-TOF-MS). Genotyping of family members was performed using an allele specific primer extension assay in combination with MALDI-TOF-MS and confirmed by conventional DNA sequencing. These studies demonstrate the broad applicability of MALDITOF-MS as a comparative screening tool applicable to the analysis of allelic gene variants. In comparison to the wild type $\alpha 1$ subunit, biochemical, electrophysiological, and confocal microscopy data indicate a reduced integration of functional $\alpha 1^{\mathrm{S} 231 \mathrm{R}}$ glycine receptors into the cell surface membrane upon recombinant expression. Apparently, the amino acid exchange S231R influences glycine receptor biogenesis and cellular trafficking by introducing a positive charge into transmembrane region TM1.

European Journal of Human Genetics (2002) 10, 188-196. DOI: 10.1038/sj/ejhg/5200779

Keywords: genotyping; glycine; hyperekplexia; MALDI-TOF-MS; receptor; startle disease

Introduction

Strychnine-sensitive glycine receptors (GlyRs) are important mediators of neuronal inhibition in mammalian brain stem

\footnotetext{
*Correspondence: C-M Becker, Institut für Biochemie, Emil-FischerZentrum, Universität Erlangen-Nürnberg, Fahrstrasse 17, D-91054 Erlangen, Germany. Tel: +49 913185 24190; Fax: +49 913185 22485; E-mail: cmb@biochem.uni-erlangen.de

${ }^{3}$ Current address: Institut für Pharmazeutische Chemie, PhilippsUniversität Marburg, D-35032 Marburg, Germany.

${ }^{4}$ These authors contributed equally to this work.

Received 15 August 2001; revised 27 December 2001; accepted 4 January 2002
}

and spinal cord where they contribute to the central control of muscle tone. Due to homology in structural architecture and functional features, GlyRs belong to the ligand gated ion channel superfamily which also includes the $\gamma$-aminobutyric acid $\left(\mathrm{GABA}_{\mathrm{A}} \mathrm{R}\right.$ and $\left.\mathrm{GABA}_{\mathrm{C}} \mathrm{R}\right)$, nicotinic acetylcholine (nAChR), and serotonin $\left(5-\mathrm{HT}_{3} \mathrm{R}\right)$ receptor. $^{1-5}$ Members of this family comprise five membrane spanning subunits surrounding a central ion pore delineated by the transmembrane segment TM2 of the monomers. Homologous to the other members of the receptor family, GlyR subunits possess a large extracellular N-terminal domain followed by four transmembrane regions (TM1-4) and a short extracellular C-terminal portion. ${ }^{6,7}$ As analysed in 
rodents, the adult GlyR isoform represents a protein complex assembled from three ligand-binding $\alpha 1$ and two structural $\beta$ subunits. ${ }^{8}$ In addition, $\alpha 2, \alpha 3$, and $\alpha 4$ subunit genes have been identified. ${ }^{9-11}$ Determinants of agonist (glycine, $\beta$-alanine, taurine) and antagonist (strychnine) binding have been assigned to the extracellular N-terminal domain of the $\alpha$ subunits. ${ }^{6}$ Glycinergic agonist responses also depend on amino acid determinants within the loops linking segments TM1 and TM2 as well as TM2 and TM3. ${ }^{12,13}$ Opening of the receptor channel is induced by agonist binding, leading to hyperpolarisation of the cell due to an influx of chloride ions.

Symptoms of the human neurological disorder, hyperekplexia (startle disease, stiff baby syndrome, STHE, OMIM \#149400 and *138491), resemble sublethal strychnine intoxication. ${ }^{14,15}$ Affected infants display extreme muscle stiffness and pronounced startle reactions which may result in fatal apneic attacks. During the first year of life, muscle tone returns to normal, while excessive startling, which may result in immediate, unprotected falling, may persist throughout life. ${ }^{15,16}$ Hyperekplexia is associated with mutations of the human GLRA1 gene encoding the GlyR $\alpha 1$ subunit. ${ }^{14,17}$ GLRA1 is localised on chromosome 5q31.2. The coding region is distributed over nine exons. ${ }^{10,18-20}$ Hyperekplexia mutations cluster in exons 7 and 8, inducing amino acid substitutions within a region ranging from TM1 to the extracellular loop connecting segments TM2 and TM3. ${ }^{17}$ While most of the hyperekplexia alleles identified follow a dominant trait, ${ }^{19,21-27}$ a recessive variant of the disease has been associated with a T1112A mutation leading to an I244N exchange at the Cterminal border of $\mathrm{TM} 1 .^{22}$ In addition to the missense alleles, a GLRA1 null mutation has been associated with recessive hyperekplexia. ${ }^{15}$ In mouse models resembling hyperekplexia, mutations of the GlyR $\alpha$ - and $\beta$-subunit genes have been identified. ${ }^{12}$

Molecular analysis of GlyR mutant alleles has largely relied on SSCP or direct sequencing of genomic DNA, both methods being time consuming and expensive. Matrix-assisted laser desorption ionisation time-of-flight mass spectrometry (MALDI-TOF-MS) has evolved into a technique widely applicable for accurate mass determination in protein chemistry. $^{28}$ Introduction of picolinic acid derivatives as matrices for the analysis of nucleic acids has expanded the advantages of MALDI-TOF-MS into molecular biology and genetic analysis. ${ }^{29,30}$ Due to the specific molecular weight of the four DNA nucleobases, the detection of DNA sequence alterations relies on comparative mass analysis. Thus, MALDI-TOF-MS combined with molecular techniques offers an excellent opportunity for mutation detection and genotyping, as well as suitability for high throughput screening.

Here, we report a novel GLRA1 mutant allele C1073G causing recessive hyperekplexia. The missense mutation results in the substitution of serine 231 for arginine in transmembrane region TM1. The mutation was detectable by MALDI-TOF-MS analysis of sequence specific restriction digests. Genotyping of the family was performed by a primer extension assay specific for the novel allele in combination with MALDI-TOF-MS. Recombinant expression studies suggested that alterations of receptor biogenesis and trafficking to the cell surface of $\alpha 1^{\mathrm{S} 231 \mathrm{R}}$ GlyRs represent the molecular defect of this mutation.

\section{Materials and methods}

\section{Patient samples and restriction digest based mutation} detection

Chromosomal DNA was extracted from EDTA-blood by means of the RapidPrep ${ }^{(i)}$ Macro Genomic DNA Isolation Kit (Pharmacia) according to the manufacturer's instruction. Three overlapping PCR fragments were generated in separate reactions using specific primer pairs. PCR No.1: forward 5'GTA AAT TCA CCT GCA TTG AGG-3', reverse 5'-ACA ATG AGC AGG CTG GG-3' PCR No.2: forward 5'-GGG TTA CTA CCT GAT TCA GAT G-3', reverse GTG GTG ATG CCT AGG CC; PCR No.3: forward 5'-GAT GCT GCA CCT GCT CG-3', reverse 5'-CTT GGC AGA GAT GCT CG-3' (all primers from MWG Biotech). Genomic DNA was denatured at $95^{\circ} \mathrm{C}$ ( $5 \mathrm{~min})$ followed by 30 cycles at $94^{\circ} \mathrm{C}(30 \mathrm{~s}), 55^{\circ} \mathrm{C}(30 \mathrm{~s})$, $72^{\circ} \mathrm{C}(30 \mathrm{~s})$, and $5 \mathrm{~min}$ at $72^{\circ} \mathrm{C}$ using an Applied Biosystems (ABI)-Perkin Elmer GeneAmp 9600 Thermocycler. Each reaction contained $200 \mathrm{ng}$ template DNA, $0.5 \mu \mathrm{M}$ of forward and reverse primer, $2.5 \mathrm{~mm} \mathrm{MgCl}_{2}, 50 \mathrm{mM} \mathrm{KCl}, 10 \mathrm{~mm}$ Tris$\mathrm{HCl}$ (pH 8.3), $300 \mu \mathrm{M}$ dNTPs and $5 \mathrm{U}$ of Taq DNA polymerase (Eurobio). PCR amplimers were purified by ethanol precipitation. PCR fragment No. 2, spanning bp 47 to bp 163 of GLRA1 exon 7, was digested with FokI (2U, NEB) and XhoII (1 U, Promega) in buffer C (Promega) in presence of $200 \mathrm{ng} / \mathrm{ml}$ acetylated bovine serum albumin at $37^{\circ} \mathrm{C}$ for $16 \mathrm{~h}$.

\section{Primer extension reaction}

Each PCR contained $0.625 \mu \mathrm{M}$ forward (5'-AGC GGC AGA TGG GTT ACT ACC TGA TT-3') and reverse primer (5'-TGG TCA TGG TGA GCA CAG TGG TGA T-3'), 50 ng of genomic DNA template, $1 \mathrm{U}$ Expand High-Fidelity in the supplied buffer 2 (Boehringer) and $200 \mu \mathrm{M}$ dNTPs. The thermal cycling conditions were $94^{\circ} \mathrm{C}$ for $4 \mathrm{~min}, 30$ cycles at $94^{\circ} \mathrm{C}$ (60 s), $55^{\circ} \mathrm{C}(30 \mathrm{~s}), 72^{\circ} \mathrm{C}(30 \mathrm{~s})$, and $72^{\circ} \mathrm{C}(3 \mathrm{~min})$. Subsequently, the samples were treated with $1 \mathrm{U}$ shrimp-alkaline phosphatase and $1 \mathrm{U}$ exonuclease $\mathrm{I}$ (Biozym) at $37^{\circ} \mathrm{C}$ (45 min) followed by heating to $96^{\circ} \mathrm{C}(5 \mathrm{~min})$. The PCR products were used for the primer extension reaction. The extension mix contained $40 \mathrm{pmol}$ forward extension primer 5'-GAT TCA GAT GTA TAT ATT CCC AG-3', 3 U Thermosequenase (Pharmacia), $400 \mu \mathrm{M}$ dGTP and $400 \mu \mathrm{M}$ ddCTP in Thermosequenase reaction buffer. Extension reactions were performed at $94^{\circ} \mathrm{C}(4 \mathrm{~min})$, and 30 cycles at $94^{\circ} \mathrm{C}(10 \mathrm{~s})$, $60^{\circ} \mathrm{C}(10 \mathrm{~s})$ and $72^{\circ} \mathrm{C}(10 \mathrm{~s})$. 


\section{MALDI-TOF-MS analysis}

Restriction digests and primer extension products were purified using pipette tips with immobilised C18 silica (ZipTips, Millipore). Tips were prewetted with 50\% (v/v) acetonitrile and equilibrated in $100 \mathrm{~mm}$ triethylammonium acetate buffer, $\mathrm{pH} 6.8$, (TEAA). After addition of TEAA to achieve a final concentration of $10 \mathrm{~mm}$, the oligonucleotides were bound to the C18 material. Immobilised oligonucleotides were washed extensively with $100 \mathrm{~mm}$ ammonium acetate, $\mathrm{pH} 6.7$, and eluted with $20 \%$ (v/v) acetonitrile. Aliquots of the purified samples were spotted onto matrix crystals of 3-hydroxypicolinic acid on a stainless steel target and air dried.

Mass determinations were performed on a Biflex ${ }^{(i m}$ III MALDI-TOF-MS (Bruker Daltonik) equipped with a nitrogen laser $(\lambda=337 \mathrm{~nm})$ and delayed extraction. Laser-desorbed positive ions were analysed following acceleration by either $20 \mathrm{kV}$ in linear or $19 \mathrm{kV}$ in reflectron mode. External calibration was performed by using an oligonucleotide mixture as a weight standard. Usually, 30 individual spectra were averaged to produce one mass spectrum.

\section{DNA sequencing}

Sequence analysis was performed using an Automatic DNA Sequencer (ABI-Perkin Elmer, 377A). The cycle sequencing reaction was performed using the ABI PRISM ${ }^{(m)}$ Dye Terminator Cycle Sequencing Kit according to the manufacturer's protocol. PCR amplimers were purified by phenol/ chloroform extraction or using the QIAquick PCR Purification Kit (Qiagen) according to the manufacturer's instructions.

\section{Site directed mutagenesis and recombinant expression}

Using a PCR-mediated site-directed mutagenesis approach, a single nucleotide exchange at position S231 was introduced into a plasmid (CMV-pRK5) carrying the $\alpha 1$ subunit cDNA of the human glycine receptor (pRK5GLRA1, wild type). ${ }^{13}$ The mutation was verified by direct sequencing. The plasmids carrying GLRA1 cDNA and the mutated variant, GLRA1 C1073G (pRK5-GLRA1 S231R), were transfected transiently into HEK293 cells $(1 \mu \mathrm{g}$ plasmid DNA $/ \mathrm{cm}^{2}$ dish) using a modified calcium-phosphate precipitation method. ${ }^{31}$ A plasmid carrying green fluorescent protein (pCMV-GFP) was co-transfected in all experiments for easy visualisation of transfected cells during electrophysiological recordings and to control for transfection efficiency. For immunoblot analysis, crude cell membranes and cell lysates were prepared from transfected cells on day 3 post-transfection. ${ }^{26,32}$ Samples were heated to $95^{\circ} \mathrm{C}$ for $10 \mathrm{~min}$, separated by SDS-PAGE (30 $\mu \mathrm{g}$ protein/ lane) and transferred to a nitrocellulose membrane. GlyR protein was detected using the monoclonal antibody $4 \mathrm{a}$ and Cy5-labelled GaM F $\left(\mathrm{ab}_{2}\right)$ (Dianova). Immunoreactivity was visualised using a phosphoimager (STORM, Molecular Dynamics).

\section{Electrophysiology}

Whole cell currents were recorded using the standard patch clamp technique. ${ }^{33}$ Signals were acquired using a EPC9 recording system (HEKA Electronics), filtered at $2.3 \mathrm{kHz}$ ( $-3 \mathrm{~dB}$ value, 8-pole Bessel filter), digitised and sampled at $10 \mathrm{kHz}$ using the Pulse data acquisition system (Digidata 1200 interface, HEKA Electronics). Recordings were made at room temperature $\left(22-24^{\circ} \mathrm{C}\right)$. Patch-electrodes were pulled from filamented borosilicate glass (Sutter, ID: $0.69 \mathrm{~mm}, \mathrm{OD}$ : $1.2 \mathrm{~mm}$ ). Final electrode resistances ranged from 3-5 M 2 . Series resistances varied from 15-25 $\mathrm{M} \Omega$ and were not compensated. For recording, coverslips with transfected cells were placed into a recording chamber and perfused at $2 \mathrm{ml} /$ min with external bath solution ( $\mathrm{pH}$ 7.4) containing $137 \mathrm{mM}$ $\mathrm{NaCl}, 5.4 \mathrm{~mm} \mathrm{KCl}, 2 \mathrm{~mm} \mathrm{CaCl}, 1 \mathrm{~mm} \mathrm{MgCl}_{2}, 5 \mathrm{~mm}$ HEPES. The intracellular solution ( $\mathrm{pH} 7.4$ ) contained $120 \mathrm{mM} \mathrm{CsCl}$, $20 \mathrm{~mm}$ TEACl, $1 \mathrm{mM} \mathrm{CaCl} 2,2 \mathrm{mM} \mathrm{MgCl}_{2}, 11 \mathrm{~mm}$ EGTA, $10 \mathrm{~mm}$ HEPES. Agonists were applied using a U-tube system. ${ }^{34}$ Fresh stocks of glycine were prepared at the day of recording and diluted to final concentrations with bath solution.

\section{Cell staining and confocal microscopy}

HEK293 cells were grown on poly-L-lysine (Sigma) coated glass coverslips (12 mm, Sarstedt) at 40000 cells/coverslip. At 3 days after transfection ( $0.25 \mu \mathrm{g}$ plasmid DNA/coverslip), cells were fixed in ice-cold methanol/acetic acid and stained using the monoclonal antibody $4 \mathrm{a}$ followed by Cy3conjugated secondary antibody (Dianova). Immunofluorescence was examined with a confocal laser scanning microscope (Molecular Dynamics).

\section{Subjects}

Patient DE is a 6-year-old son of apparently healthy consanguineous parents of Iranian origin (Figure 1). Three days after birth, DE became conspicuous by nocturnal generalised jerks accompanied by short-windedness and slight trembling. Initially, these states were interpreted as grand mal seizures and he was subjected to anticonvulsive therapy first with clonazepam following a combination of phenobarbitone and carbamazepin. At 2 years of age, he became free of fits. In 1996, the boy was admitted to the North German centre of epilepsy for assessment because of a tendency to fall leading to injuries and fractures. The boy displayed increased muscle proprioceptive reflexes, exaggerated head retraction jerks, myocloni, and atactic gait disturbances. In one incident, a fall occurred caused by a severe startle reaction upon sudden opening of a door during physical examination. Social behaviour was reportedly impaired due to considerable fear of unexpected falling. EEG recordings were normal. Treatment with clonazepam resulted in amelioration of clinical symptoms within days. DE exhibited mild mental retardation. The 8-year-old sister of DE did not exhibit any neurological symptoms. Further relatives were not available for examination. 


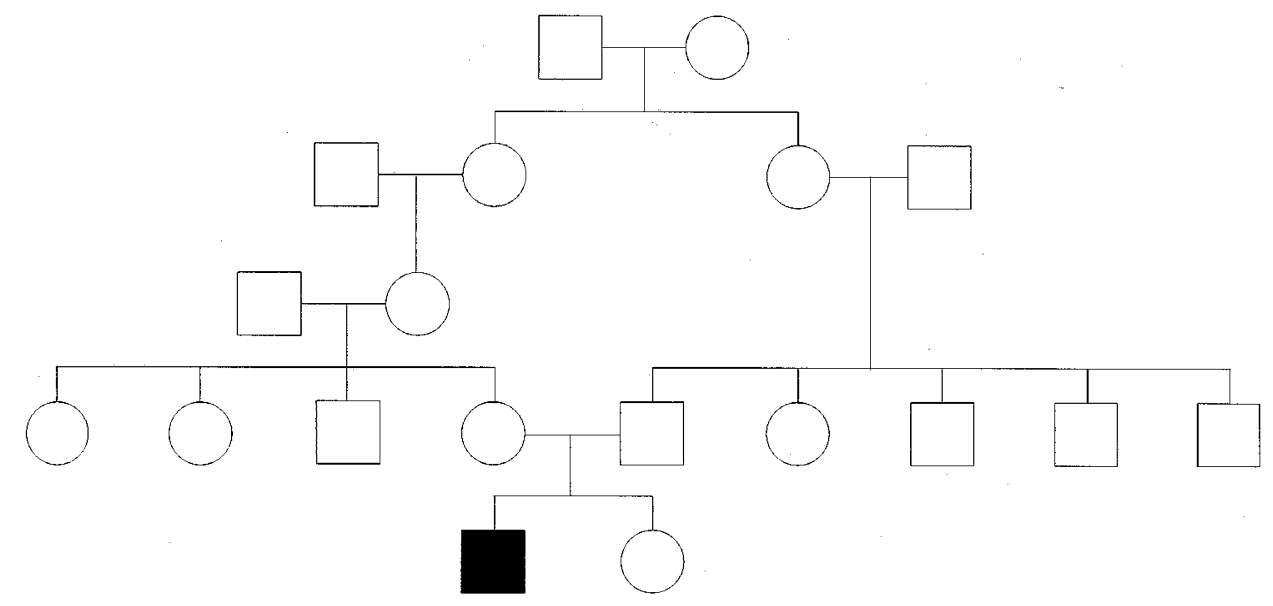

Figure 1 Pedigree of the family of DE. The filled symbol represents patient DE; birth order was altered to preclude identification of participating subjects.

\section{Results}

Hyperekplexia or startle disease (STHE) is a neurological disorder characterised by infantile muscle hypertonia and exaggerated startle responses. ${ }^{19}$ Dominant and recessive forms of this disorder have been identified, most of which are caused by point mutations of the GLRA1 gene. ${ }^{5}$ Suffering from an apparently recessive form of hyperekplexia, patient $\mathrm{DE}$ is a 6-year-old son of consanguineous parents of Iranian origin (Figure 1). To assess the genetic basis of this hyperekplexia variant, we focused on exon 7 of GLRA1 (exon numbering according to ${ }^{26}$ ), the most probable region for a mutation, for the novel MALDI-TOF-MS based DNA screening approach.

Overlapping amplimers of $120 \mathrm{bp}$ were generated in three separate PCRs completely covering exon 7 (nucleotide positions 994-1208), each providing mutation information on DNA stretches of approximately $80 \mathrm{bp}$. Purified PCR products were digested with restriction enzymes to generate a defined set of oligonucleotides. For example, PCR fragment no. 2 was digested with FokI and XhoII, producing four sense and four antisense fragments of defined masses (Figure 2A). A control individual referred to as wild type produced an identical restriction digest mass pattern (Figure 2B, upper spectrum). All expected peaks as well as the remaining PCR primers were detected with a maximal mass difference of less than 3 Da from theoretical values (Figure 2C). In the MALDITOF-MS spectrum of patient DE, all wild type peaks were recovered except for the two peaks representing fragments $2 \mathrm{~s}$ and $1 \mathrm{a}$. In comparison to the control DNA mass pattern, two additional peaks had appeared with a mass difference of about $40 \mathrm{Da}$, compatible with a point mutation in the $4 \mathrm{bp}$ overlapping segments of fragment 2s and 1a (nt 1072-1075; sense: GCCT; antisense: AGGC). As the nucleotides cytosine and guanosine possess a mass difference of $40 \mathrm{Da}$, the increase in molecular mass of fragment $1 \mathrm{a}$ and corresponding decrease of fragment 2 s of about $40 \mathrm{Da}$ as compared to the wild type mass signals indicated a $C$ to $G$ exchange at nucleotide position 1073 or 1074 . It should be noted that the restriction enzym FokI cleaves DNA 13 bases upstream of its recognition sequence CATCC. For this reason, FokI may cut DNA even when the cleavage site is mutated.

To specify the position of the mutation, genomic DNA sequencing of GLRA1 exon 7 was performed. We thus identified a $\mathrm{C}$ to $\mathrm{G}$ transversion at position 1073 of the open reading frame leading to a non conservative amino acid substitution of serine 231 for arginine in transmembrane region TM1 of the GlyR $\alpha 1$ subunit. Based on this information, patient DE and his family were genotyped for the novel GLRA1 allele by site-specific primer extension reactions and MALDI-TOF-MS analysis of the extension products (Figure 3). The forward extension primer used for the determination of nucleotide position 1073 produced a peak corresponding to a molecular mass of $6421 \mathrm{Da}$. The extension primer was designed to anneal to the target DNA directly in front of the mutation site. In case of the wild type sequence, incorporation of a ddCTP was found to terminate the primer extension reaction, thereby extending the primer to a mass of $6694 \mathrm{Da}$. On the other hand, when a $\mathrm{C}$ to $\mathrm{G}$ exchange was present, the primer was elongated by a dGTP and terminated in the next extension step by incorporation of the following ddCTP, producing a mass of 7023 Da (Figure $3 \mathrm{~A})$. In contrast to the wild type allele (6694 Da), patient DE was found to be homozygous for the mutation with a single mass peak of $7023 \mathrm{Da}$ detectable (Figure 3B). All nonsymptomatic members of the family analysed were found to be heterozygous for the allele as indicated by the presence of both peaks of 6694 and 7023 Da, respectively (Figure 3B). The unextended primers remaining from the extension reaction served as an internal calibration standard. All of the MALDI-TOF-MS based genotyping results were confirmed 


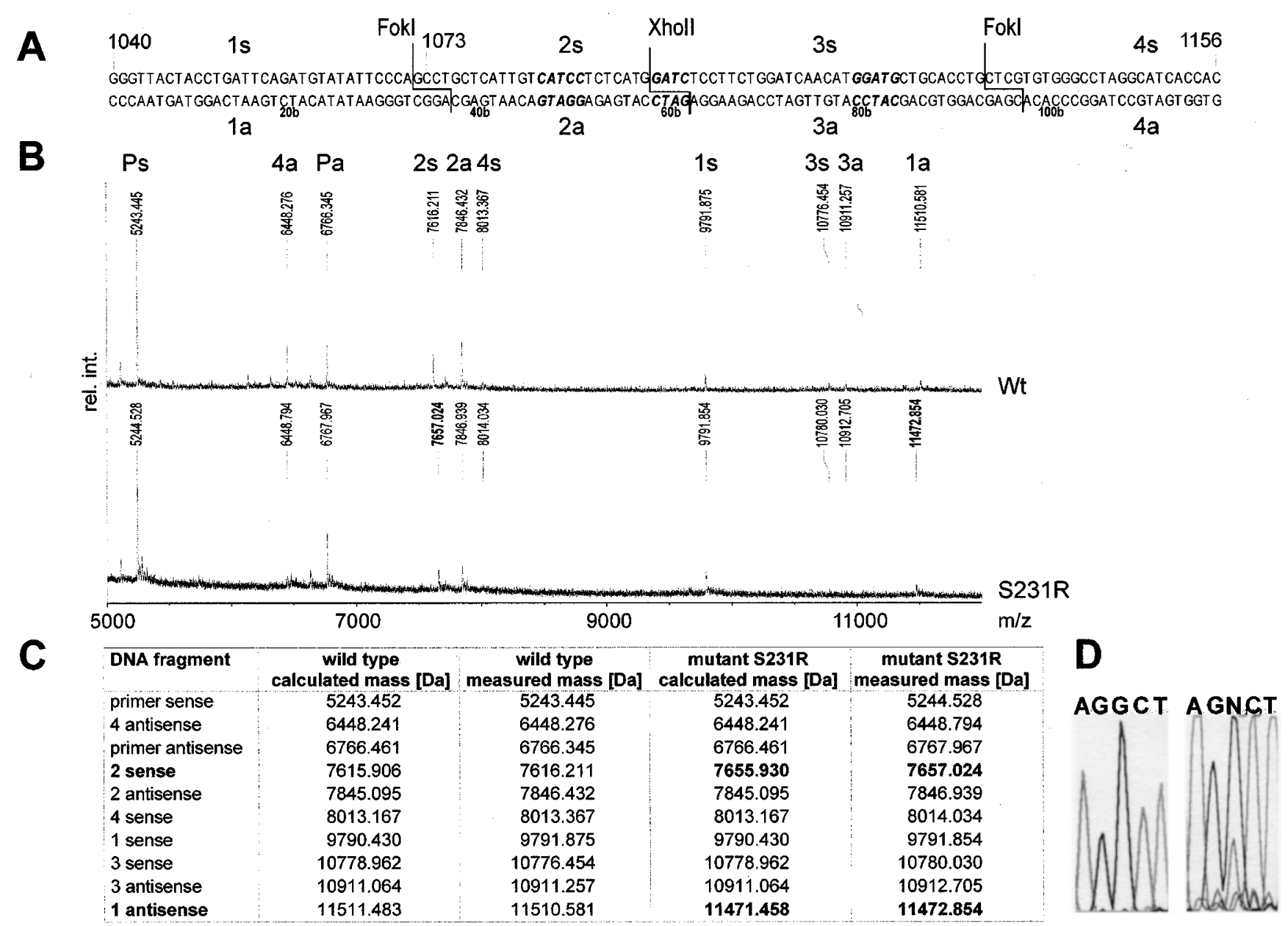

Figure 2 Restriction based mutation detection of a GLRA1 mutant allele by MALDI-TOF-MS. (A) Sequence of wild type DNA fragment of GLRA1 exon7 No.2 (bp 1040-1156) including the restriction sites for Fokl and Xholl. While Xholl possesses recognition and cleavage sites at an identical position, Fokl cuts 13 bp upstream of its recognition sequence CATCC. Recognition sequences are shown in bold italic. The resulting theoretical fragments are numbered from $1 \mathrm{~s}$ (sense) to $4 \mathrm{~s}$ and $1 \mathrm{a}$ (antisense) to $4 \mathrm{a}$, respectively. (B) MALDI-TOF-MS spectra of GLRA1 exon 7 PCR No.2 (bp 1040-1156) digested with Fokl and Xholl: Samples from control individual (top) and patient DE (bottom). The informative peaks are labelled by $1 \mathrm{~s}$ to $4 \mathrm{~s}, 1 \mathrm{a}$ to $4 \mathrm{a}$ and PCR primers by Ps and Pa. The peaks of $7657.024 \mathrm{Da}$ and $11472.854 \mathrm{Da}$ displaying the GLRA1(C1073G) allele are presented in bold. (C) Calculated and measured masses of DNA fragments from GLRA1 (exon 7 , no. 2 , bp 47-163) wild type and allele C1073G after restriction digest. Fragment 2 sense (C to $\mathrm{G}$ exchange, $\Delta \mathrm{m}=+40.024 \mathrm{Da})$ and fragment 1 antisense ( $G$ to $C$ exchange, $\Delta m=-40.024 \mathrm{Da}$ ) cover the mutation S231R. (D) Sequencing results of DNA fragments from GLRA1 (exon 7): Reverse sequences (nt 1075-1071) of wild type DNA (left panel) and DNA heterozygous for allele C1073G (right panel) are depicted.

by conventional DNA sequencing. The wild type and the heterozygous DNA for the C1073G allele are depicted in Figure 2D. This sequence motif has not been found in more than 130 unrelated individuals, excluding this exchange to be a common population polymorphism.

For functional analysis, the mutation C1073G was introduced by site directed mutagenesis into a plasmid carrying the complete GLRA1 cDNA. Wild type and mutated plasmid were transiently transfected into HEK293 cells. Crude cell membranes and cell lysates were analysed by immunoblotting using the monoclonal antibody $4 \mathrm{a}$ (mAb4a) which recognises an N-terminal extracellular epitope of GlyR $\alpha 1$ (aa
$96-105,{ }^{35}$, Figure $\left.4 \mathrm{~A}\right)$. A marked reduction of receptor expression was observed in membrane fractions from cells transfected with the mutant plasmid $\left(\right.$ GlyR $\left.\alpha 1^{\text {S231R }}\right)$ compared to cells carrying GlyR $\alpha 1$ (Figure $4 \mathrm{~A}$, lanes 1 and 2). In contrast, overall receptor expression was indistinguishable for whole cell lysates (Figure 4A, lanes 3 and 4), indicating that surface accumulation of GlyR $\alpha 1$ was affected by the mutation.

For further functional characterisation of mutant $\alpha 1^{\text {S231R }}$ GlyRs, whole cell glycinergic currents were recorded from transfected cells. ${ }^{34}$ Cells carrying GlyR $\alpha 1^{\text {S231R }}$ exhibited a strong reduction of the maximal current $\left(\mathrm{I}_{\max }\right)$ as compared to cells transfected with the wild type construct (Figure 4B), 
A w

5'- TACCTGATT CAGATGTATATTCCCAGCCTGCTC-3

3'- ATGGACTAAGTCTACATATAA GGGTCGGACGAG-5

C1073G (S231R)

5' - TACCTGATT CA GATGTATATT CCCAGGCTGCTC- 3'

3' - AT GGACTAAGTCTACATATAA GGGTCEGACGA G- 5 ,

extension primer forward

GAT T CA G T G T T A T C C A G $\quad$ 6421 Da

extension: dGTP and ddCTP

extension product: $W_{t}$

GATTCA A T GTATATTCCCAGC $\quad 6694 \mathrm{Da}$

extension product: C1073G (S231R)

GAT T CA A T G T A T A T C C A G G 7023 Da

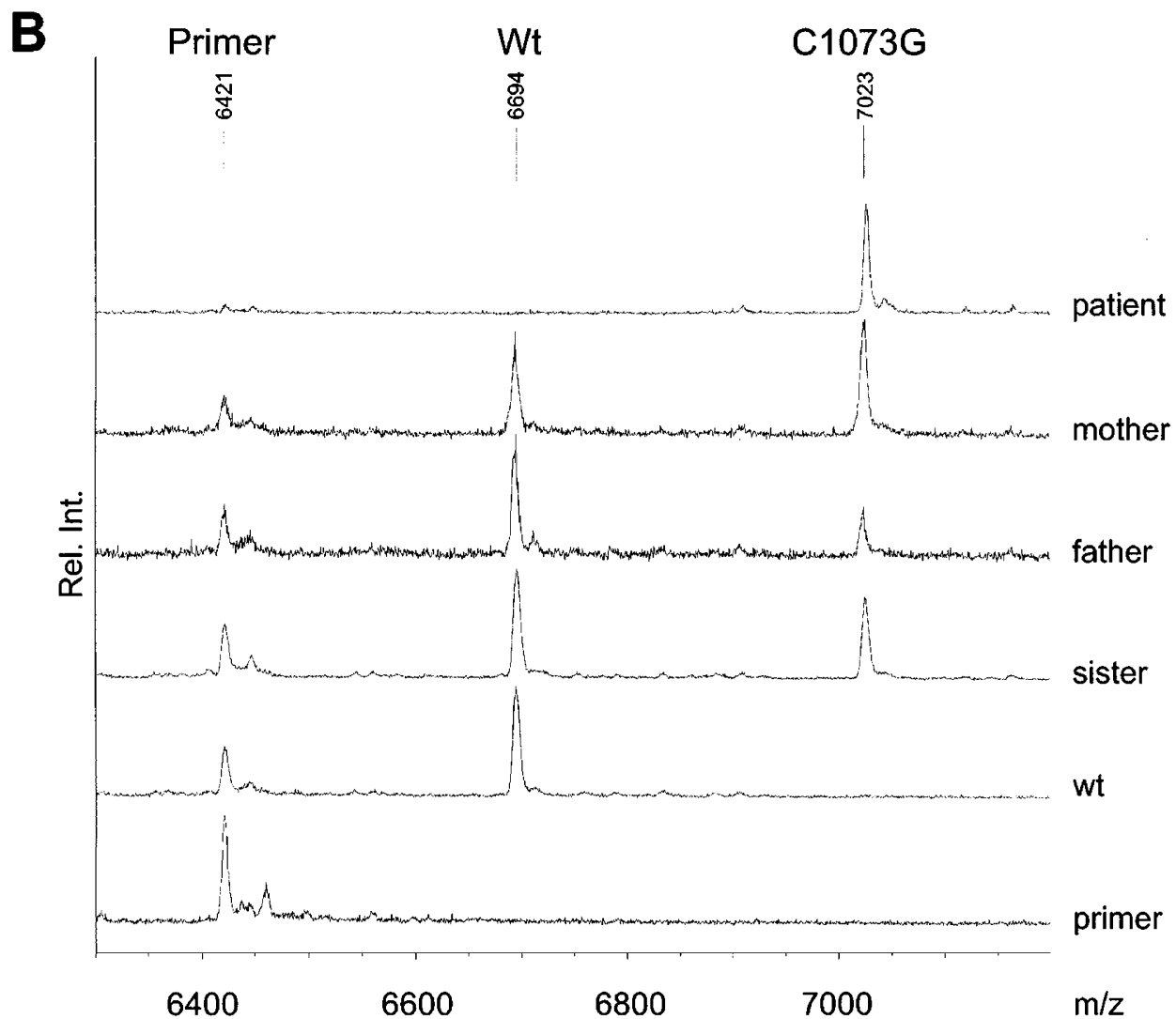

Figure 3 MALDI-TOF-MS based genotyping of allele GLRA1 C1073G. (A) Schematic design of the primer extension reaction for allele GLRA1 C1073G. (B) MALDI-TOF-MS spectra of patient DE and his sister, mother and father, a healthy control person, and the primer without extension reaction (from top to bottom). The unextended primer possesses a molecular mass of $6421 \mathrm{Da}$. The wild type allele is represented by the molecular mass of $6694 \mathrm{Da}$, whereas the mass of $7023 \mathrm{Da}$ is indicative for the point mutation C1073G.

consistent with an altered accumulation of functional mutant GlyRs on the cell surface.

Confocal microscopy of transfected HEK293 cells immunostained with mAb4a was performed to analyse the subcellular distribution of wild type and mutant receptors. Consistent with recording data, cells transfected with wild type GlyR exhibited strong immunoreactivity at the circumference of the cell, indicating a predominant localisation in 

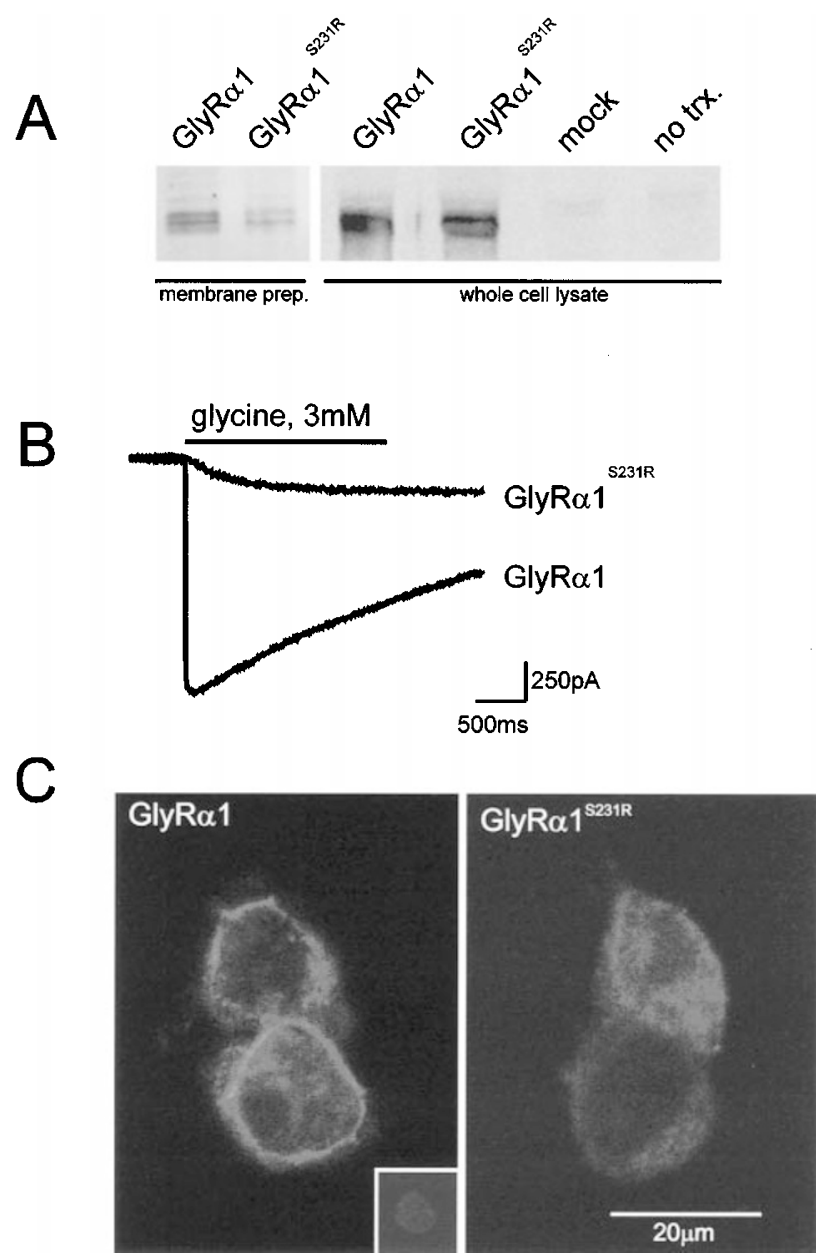

Figure 4 Functional characterisation of the GlyR $\alpha 1^{\mathrm{S} 231 \mathrm{R}}$. (A) Immunochemical detection of recombinant GlyR $\alpha 1$ and GlyR $\alpha 1^{\mathrm{S} 231 \mathrm{R}}$ receptors in membrane fractions and in whole cell lysates. Crude membrane fractions and whole cell lysates of HEK293 cells transfected with GlyR $\alpha 1$ or GlyR $\alpha 1^{\text {S231R }}$ were separated by PAGE and GlyRs visualised by immunoblotting using the GlyR-specific monoclonal antibody mAb4a. In membrane fractions, the signal at $45 \mathrm{kD}$ was weaker with mutant receptors than with wild type receptors (left panel). In contrast, intensities of immune signals were comparable for both receptors in whole-cell lysate preparations (right panel). Mock treated cells transfected with CMV-GFP and untreated cells (not exposed to plasmid DNA) served as controls.

(B) Patch-clamp analysis of HEK293 cells expressing GlyR $\alpha 1$ or GlyR $\alpha 1^{\text {S231R }}$. Glycine-induced whole cell currents were recorded from HEK293 cells $48-72 \mathrm{~h}$ following transfection using a saturating concentration of agonist ( $3 \mathrm{~mm}$ glycine). Cells transfected with the mutant plasmid displayed a strong reduction in the maximum current, $I_{\max }\left(I_{\max } S 231 R\right.$ : $69.9 \pm 23.3 \mathrm{pA}$, range: $14-219 \mathrm{pA}, n=9$ cells; $I_{\max }$ wild type: $6.3 \pm 1.6 \mathrm{nA}$, range: $1.8-12 \mathrm{nA}, n=7$ cells; $P<0.001, t$-test).

(C) Confocal microscopy of cells expressing GlyR $\alpha 1$ or GlyR $\alpha 1^{\mathrm{S} 231 \mathrm{R}}$. Confocal laser scanning microscopy of transfected HEK293 cells immunostained with mAb 4a was performed to analyse subcellular distribution of wild type and mutant receptors. In cells transfected with wild type GlyR, mAb4a the plasma membrane (Figure 4C, left panel). In cells transfected with the mutant $\alpha 1^{\mathrm{S} 231 \mathrm{R}}$, most of the receptor antigen was intracellular (Figure $4 \mathrm{C}$, right panel).

\section{Discussion}

As allelic variants of the human GLRA1 gene underlie the neurological disorder hyperekplexia (reviewed in: ${ }^{14,17}$ ), genetic screening for hyperekplexia alleles has become a highly informative tool supporting the clinical diagnosis of hypertonic disorders. However, a routine screening for candidate alleles essentially depends on both, a comprehensive knowledge of disease associated genetic polymorphisms as well as efficient and reliable detection systems. Single stranded conformation polymorphism (SSCP) analysis has been widely used to screen patients suffering from different hereditary disorders for allelic gene variants. ${ }^{25}$ As this analysis relies on electrophoretic mobility shifts of two species of partially refolded single stranded DNA, changing temperature conditions or even minor sequence alterations may affect informative DNA secondary structures. Although compared to DNA sequencing, SSCP possesses low detection rates ( $\mathrm{ca}$. 70\%), it represents a first approach for genetic characterisation due to its simplicity and low costs. In contrast, direct DNA sequencing using the dideoxy nucleotide technique is most reliable, yet time consuming and expensive. Moreover, determination of heterozygous alleles still remains a difficult task with simultaneous bands influencing the mutual intensities on the sequencing gel.

MALDI-TOF-MS offers a direct approach to DNA analysis of defined sequences. The combination of PCR, restriction digests and analysis by MALDI-TOF-MS, should be a suitable way to detect unknown mutations. While mass differences between mutant and reference spectra are indicative of alterations of nucleotide sequences, reliability of MALDITOF-MS analysis is further enhanced by the fact that both, the DNA sense and antisense strand generated by PCR and digest, are measured simultaneously. Except for an inversion, an altered DNA sequence will result in a mass shift of a peak or an appearance of a novel peak. The occurrence of a second complementary shift or peak is sufficient for the unambiguous detection of a genetic variant. As the human genome project progresses, more and more attention is paid to the genetic heterogeneity of individuals and populations. ${ }^{36}$ It is expected that single nucleotide polymorphisms (SNP) emerge with a frequency of at least $1: 1000$. MALDI-TOFMS analysis of SNPs or point mutations offers the potential for reliable high-throughput screening. Here, the application

immunoreactivity was detected at the circumference of the cell (left panel, insert: control staining without primary antibody). In contrast, in cells transfected with mutant $\alpha 1^{\mathrm{S} 231 \mathrm{R}}$, the antigen was localised to intracellular compartments mostly (right panel). 
of a primer extension assay to determine the GLRA1 (C1073G) mutation in a patient and his family has been successful. Both alleles were reliably distinguishable as the peaks representing the alleles had a mass difference of about $300 \mathrm{Da}$. This analysis shows that MALDI-TOF-MS is applicable to detect unknown mutations, and for a fast and reliable analysis of known genetic variations. A note of caution, however appears warranted: Due to suppression effects of DNA species differing over a broad range in molecular mass, detectability of restriction fragment patterns is restricted to digests producing a limited number of informative fragments.

Most of the GLRA1 point mutations known are associated with dominant forms of hyperekplexia, suggesting that the incorporation of mutated subunits into the final pentameric complex either leads to gain of function effects or to non functional GlyRs. Previously, the recessive mutant allele GLRA1 (I244N) has been identified, ${ }^{22}$ decreasing apparent affinities for glycine, taurine and $\beta$-alanine by a factor of 10 to 15 as compared to the wild type. ${ }^{37}$ While mutant GlyR $\alpha 1^{1244 \mathrm{~N}}$ receptors desensitise significantly faster than the wild type receptors, the same study provided strong evidence for an impaired expression or stability of the mutant subunit. The novel point mutation GLRA1 (S231R) likewise causes a recessive form of hyperekplexia. Our biochemical and electrophysiological data suggest that the allele GLRA1 (S231R) produces functional GlyRs. Prediction of transmembrane topology of the nicotinic acetylcholine receptor family places the mutant site within TM1 of the GlyR $\alpha 1$ subunit. ${ }^{12}$ Accordingly, introduction of volume and/or positive charge would destabilise nascent receptor subunits and interfere with intracellular routing to the plasma membrane. Based on protease accessibility studies combined with mass spectrometry, however, Leite e $_{\text {al }}{ }^{38}$ recently published an alternative topological model of the GlyR placing amino acid position 231 within a $\beta$-sheet structure starting with Y227. Accordingly, flanking N-terminal amino acids might interact with the mouth of the channel. This would be in agreement with studies on the acetylcholine receptor where homologous residues block channel activity in the closed state. ${ }^{39}$ In this scenario, residue S231 would be located within the membrane, close to the extracellular surface. Thus, the mutation GlyR $\alpha 1^{\mathrm{S} 231 \mathrm{R}}$ may prohibit correct protein folding as the positively charged residue R231 remains near the membrane. In either case, altered intracellular trafficking of nascent $\alpha 1^{\text {S231R }}$ GlyRs is supported by a dramatic reduction of receptor insertion into plasma membrane and altered channel functionality. These observations suggest that the recessive phenotype may be a consequence of a dramatic loss of functional receptor in the homozygous state.

\section{Acknowledgments}

We thank the members of family DE for participation in this study. Excellent technical assistance by Angelien Heister and Renate Fäcke-
Kühnhauser is gratefully acknowledged. We thank Sevinc Özbey for performing SSCP-analysis and Silke Seeber for help with confocal microscopy. We are grateful to Dr Markus Kostrzewa, Bruker Saxonia Analytik GmbH (Leipzig, Germany) for helpful discussions. We thank Bruker Daltonik GmbH (Bremen, Germany) for support by providing the MALDI-TOF mass spectrometer Biflex III. This work was supported by Deutsche Forschungsgemeinschaft, Bundesministerium für Bildung und Forschung, the Commission of the European Union, Fonds der Chemischen Industrie.

\section{References}

1 Grenningloh G, Rienitz A, Schmitt B et al: The strychninebinding subunit of the glycine receptor shows homology with nicotinic acetylcholine receptors. Nature 1987; 328: 215-220.

2 Uetz P, Abdelatty F, Villarroel A, Rappold G, Weiss B, Koenen M: Organisation of the murine 5-HT3 receptor gene and assignment to human chromosome 11. FEBS Lett 1994; 339: 302-306.

3 Enz R, Cutting GR: Molecular composition of $\mathrm{GABA}_{\mathrm{C}}$ receptors. Vision Res 1998; 38: 1431-1441.

4 Vafa B, Schofield PR: Heritable mutations in the glycine, GABAA, and nicotinic acetylcholine receptors provide new insights into the ligand-gated ion channel receptor superfamily. Int Rev Neurobiol 1998; 42: 285 - 332.

5 Breitinger HG, Becker C-M: The inhibitory glycine receptor: prospects for a therapeutic orphan? Curr Pharm Des 1998; 4: $315-334$.

6 Betz H: Structure and function of inhibitory glycine receptors. $Q$ Rev Biophys 1992; 25: 381-394.

7 Bormann J, Rundström N, Betz H, Langosch D: Residues within transmembrane segment M2 determine chloride conductance of glycine receptor homo- and hetero-oligomers. EMBO J 1993; 12: $3729-3737$

8 Langosch D, Becker C-M, Betz H: The inhibitory glycine receptor: a ligand-gated chloride channel of the central nervous system. Eur J Biochem 1990; 194: 1-8.

9 Grenningloh G, Schmieden V, Schofield PR et al: Alpha subunit variants of the human glycine receptor: primary structures, functional expression and chromosomal localization of the corresponding genes. EMBO J 1990; 9: 771-776.

10 Matzenbach B, Maulet Y, Sefton L et al: Structural analysis of mouse glycine receptor alpha subunit genes. Identification and chromosomal localization of a novel variant. J Biol Chem 1994; 269: $2607-2612$

11 Nikolic Z, Laube B, Weber RG et al: The human glycine receptor subunit alpha3. Glra3 gene structure, chromosomal localization, and functional characterization of alternative transcripts. $J$ Biol Chem 1998; 273: 19708 -19714.

12 Becker C-M, Langosch D: The inhibitory glycine receptor; in Stephensen FA, Turner AJ (eds): Amino Acid Neurotransmission. London: Portland, 1997, pp 93-112.

13 Breitinger HG, Villmann C, Becker K, Becker C-M: Opposing effects of molecular volume and charge at the Hyperekplexia site alpha1 (P250) govern glycine receptor activation and desensitization. J Biol Chem 2001; 6: 6.

14 Becker C-M: Glycine receptors: molecular heterogenity and implications for disease. The Neuroscientist 1995; 1: 130-141.

15 Brune W, Weber RG, Saul B et al: A GLRA1 null mutation in recessive hyperekplexia challenges the functional role of glycine receptors. Am J Hum Genet 1996; 58: 989-997.

16 Ryan SG, Buckwalter MS, Lynch JW et al: A missense mutation in the gene encoding the alpha 1 subunit of the inhibitory glycine receptor in the spasmodic mouse. Nat Genet 1994; 7: 131-135.

17 Becker K, Becker C-M, Breitinger HG: The inhibitory glycine receptor as a model of hereditary channelopathies, in Channelopathies. Lehmann-Horn F, Jurkat-Roth K (eds): Common Mechanisms in Aura, Arrhythmia and Alkalosis. Elsevier Science BV, 2000, pp 199-222. 
18 Warrington JA, Bailey SK, Armstrong E et al: A radiation hybrid map of 18 growth factor, growth factor receptor, hormone receptor, or neurotransmitter receptor genes on the distal region of the long arm of chromosome 5. Genomics 1992; 13: $803-808$.

19 Shiang R, Ryan SG, Zhu YZ, Hahn AF, O'Connell P, Wasmuth JJ: Mutations in the alpha 1 subunit of the inhibitory glycine receptor cause the dominant neurologic disorder, hyperekplexia. Nat Genet 1993; 5: 351-358.

20 Baker E, Sutherland GR, Schofield PR: Localization of the glycine receptor alpha 1 subunit gene (GLRA1) to chromosome 5q32 by FISH. Genomics 1994; 22: 491- 493.

21 Schorderet DF, Pescia G, Bernasconi A, Regli F: An additional family with Startle disease and a G1192A mutation at the alpha 1 subunit of the inhibitory glycine receptor gene. Hum Mol Genet 1994; 3: 1201.

22 Rees MI, Andrew M, Jawad S, Owen MJ: Evidence for recessive as well as dominant forms of startle disease (hyperekplexia) caused by mutations in the alpha 1 subunit of the inhibitory glycine receptor. Hum Mol Genet 1994; 3: 2175 - 2179.

23 Shiang R, Ryan SG, Zhu YZ et al: Mutational analysis of familial and sporadic hyperekplexia. Ann Neurol 1995; 38: 85-91.

24 Elmslie FV, Hutchings SM, Spencer V et al: Analysis of GLRA1 in hereditary and sporadic hyperekplexia: a novel mutation in a family cosegregating for hyperekplexia and spastic paraparesis. J Med Genet 1996; 33: $435-436$.

25 Milani N, Dalpra L, del Prete A, Zanini R, Larizza L: A novel mutation (Gln266 $\rightarrow$ His) in the alpha 1 subunit of the inhibitory glycine-receptor gene (GLRA1) in hereditary hyperekplexia. Am J Hum Genet 1996; 58: 420-422.

26 Saul B, Kuner T, Sobetzko D et al: Novel GLRA1 missense mutation (P250T) in dominant hyperekplexia defines an intracellular determinant of glycine receptor channel gating. $J$ Neurosci 1999; 19: 869-877.

27 Moorhouse AJ, Jacques P, Barry PH, Schofield PR: The startle disease mutation Q266H, in the second transmembrane domain of the human glycine receptor, impairs channel gating. Mol Pharmacol 1999; 55: 386-395.

28 Karas M, Hillenkamp F: Laser desorption ionization of proteins with molecular masses exceeding 10000 daltons. Anal Chem 1988; 60: 2299-2301.
29 Wu KJ, Steding A, Becker CH: Matrix-assisted laser desorption time-of-flight mass spectrometry of oligonucleotides using 3hydroxypicolinic acid as an ultraviolet-sensitive matrix. Rapid Commun Mass Spectrom 1993; 7: 142-146.

30 Bonk T, Humeny A: MALDI-TOF-MS analysis of protein and DNA. Neuroscientist 2001; 7: 6-12.

31 Chen C, Okayama H: High-efficiency transformation of mammalian cells by plasmid DNA. Mol Cell Biol 1987; 7: $2745-2752$.

32 Kling C, Koch M, Saul B, Becker C-M: The frameshift mutation oscillator Glra1 spd-ot produces a complete loss of glycine receptor alpha1-polypeptide in mouse central nervous system. Neuroscience 1997; 78: 411-417.

33 Hamill OP, Marty A, Neher E, Sakmann B, Sigworth FJ: Improved patch-clamp techniques for high-resolution current recording from cells and cell-free membrane patches. Pflugers Arch 1981; 391: $85-100$.

34 Alkondon M, Albuquerque EX: Diversity of nicotinic acetylcholine receptors in rat hippocampal neurons. I. Pharmacological and functional evidence for distinct structural subtypes. Pharmacol Exp Ther 1993; 265: 1455 - 1473.

35 Schröder S, Hoch W, Becker CM, Grenningloh G, Betz H: Mapping of antigenic epitopes on the alpha 1 subunit of the inhibitory glycine receptor. Biochemistry 1991; 30: 42-47.

36 Schiebel K, Meder J, Rump A et al: Elevated DNA sequence diversity in the genomic region of the phosphatase PPP2R3L gene in the human pseudoautosomal region. Cytogenet. Cell Genet 2000; 91: 224-230.

37 Lynch JW, Rajendra S, Pierce KD, Handford CA, Barry PH, Schofield PR: Identification of intracellular and extracellular domains mediating signal transduction in the inhibitory glycine receptor chloride channel. EMBO J 1997; 16: 110-120.

38 Leite JF, Amoscato AA, Cascio M: Coupled proteolytic and mass spectrometry studies indicate a novel topology for the glycine receptor. J Biol Chem 2000; 275: 13683 - 13689.

39 Karlin A, Akabas MH: Toward a structural basis for the function of nicotinic acetylcholine receptors and their cousins. Neuron 1995; 15: $1231-1244$. 